I would commend to the Editor the coloured film prepared at the Middlesex Hospital showing the treatment of burns with the simplest of apparatus -an irrigator, water-soluble sulphonamide cream and oil silk dressings, a simple technique that needs little skilled attention, and to the value of which the reviewer can testify.

A good deal of Part II is occupied by descriptions of anaesthetic apparatus, but nowadays a surgeon scarcely dares criticise anaesthesia, even though his efforts may be frustrated by its defects. On the other hand, it must be readily admitted that many operations are not only rendered feasible but even comparatively easy because of the great advances that have been made in the administration of anaesthetics. The Oxford inhaler is an ingenious gadget with its use of the phenomena of latent heat.

It is a matter of regret that in the very excellent articles on wound treatment, the use of Penicillin is scarcely touched upon. Perhaps in future editions, or even in the appendix, it may be possible to obtain an article by one of the military surgeons who has had experience in its use.

Fig. 273 ought to be replaced by one either showing the instruments covered by a sterile towel, or the nurse's mouth and nose covered by a "sprayproof" mask. It seems inevitable that in any hospital ward dressings must be done, and the trolley system, like so many other institutions, can be improved without necessarily being scrapped.

In Part III, the chapter on Heparin is especially interesting as being rather ahead of time, since many of the conclusions are the result of animal experiments that so far have not been confirmed in man.

The loss of Sir de Courcy Wheeler will be a blow to the Editors, for he was a lucid writer with an original outlook.

In criticising the article on the Thomas's splint, one regrets the absence of the use of a foot-piece to prevent the heel resting on the bed, with consequent displacement of the foot forward in the splint.

The chapter on amputations shows originality and an independence of the limb makers, but whether this will make for the comfort of the patient may be disputed.

In spite of the advocacy of weight-bearing stumps they seem to give their owners a lot of trouble. Whether this is due to faulty limb fitting is worth considering in the light of American experience.

In future editions it is to be hoped that the chapter on amputations, which, in its ultimate results, may be the most important of all chapters, will be entrusted to a surgeon who has had considerable experience at Roehampton, but who, as Elmslie always urged, is willing to co-operate with, but not to be dominated by, the limb fitters.

This work will be of the greatest service to all who have to deal with war wounds, whether as young surgeons starting their career, or old ones manning the "home front," and the remaining parts will be welcomed with eagerness.

\section{PREVENTION AND TREATMENT OF DISEASES IN WARM CLIMATES}

By T. Gerald Garry, M.B.E., M.D. Medical Publications, London. 1944. Price 8s. 6d.

This concise little book sets out to inform the lay public about the prevention and treatment of Tropical Diseases.
It is no easy task for any author to present a technical subject in language easily grasped by all. Dr. Garry has largely succeeded by presenting the subject in two parts. Part I deals with such vital points as food, water, exercise, clothing and personal preventive measures against tropical disease, while Part 2 gives a brief up-to-date review in simple language of the diseases most commonly encountered.

This little book links in an admirable way with the Synopsis of Tropical Medicine published in 1943 by Sir Philip Manson-Bahr in response to requests for a guide to Tropical Medicine in condensed form.

It is a pity that Dr. Garry has made no reference to Relapsing Fever, and to the recently discovered D.D.T. fumigation method against lice, bugs, fleas and other insect pests. Nor does he stress sufficiently the use of Pyrethrum spraying as a malaria preventive measure. A reference to the recently introduced water-filter canvas bag for individual serving soldiers could well find a place in future editions and no up-to-date book, however small, should omit a reference to Penicillin.

Apart from these minor omissions, readers of the Journal who are likely to be proceeding eastward are advised to read Dr. Garry's little book, for they will glean many useful, practical hints not usually contained in more stereotyped text books.

\section{DISEASES OF THE NOSE, THROAT AND EAR 3rd Edition}

By I. Samson Hall. E. w S. Livingstone, Edinburgh. 1944. Price I5s. net.

A third edition of Diseases of the Nose, Throat and Ear by Dr. Simson Hall within a few years is sufficient indication of its popularity. The book is of a size which should recommend it to students, being, as prescribed also for a lady's dress, short but long enough to cover the subject. The student will find all that be can reasonably be expected to know, and the advice given is always based on sound practice, though sometimes lacking the detail for which a book of reference may be required. Some inaccuracies which had found their way into earlier editions have been corrected. There are, however, places which might still be improved. The descriptions for example of the rare condition of Pemphigris of the Pharynx and Pachydermia of the Larynx do not compensate for their extreme brevity by an irreproachable precision. The description of tracheotomy, which does not differentiate between an emergency in childhood and the deliberate procedure which can usually be adopted for an adult, will not be very helpful to the house surgeon either in the execution or after-treatment of this vital operation. For sections on the Accessory Sinuses of the Nose, and on the Ear, the diseases of which provide so large a part of the work in a special department, high praise must be given for the accurate descriptions. A fuller account of the cerebrospinal fluid and the changes which it undergoes in the intracranial complications is needed however.

This book has now established itself as a student's favourite, a position which it duly merits, and we desire only to indicate a few directions in which further improvement is possible. It may not be out of place, therefore, also to remind the author that menthol can no longer be obtained, and it is doubtful whether its absence from the dispenser's list of drugs has deprived patients of any comfort. 